\title{
Chicory vs. Zinc: The Protective Role in Alcohol-Induced Acute Liver Injury
}

\author{
Ali Abdel Rahmman', Soha Soliman², Maha A. Fahmy ${ }^{3^{*}}$ \\ 'Department of Gastroenterology, 2Department of Histology, 32Department of Anatomy and Embryology, \\ Faculty of Medicine, South Valley University
}

\begin{abstract}
Background: Ethanol is a natural product of plant fermentation. It is used as an antibacterial substance, food addictive, and alcoholic beverages. Excessive consumption of ethanol can lead to degenerative effects in many organs. Aim: To compare between the effect of zinc and chicory (Cichorium intybus) as protective agents in alcohol-induced liver damage. Material and Methods: Forty male albino rats (150-200g) were divided into four groups (10 rats each):group1(control group), group 2:rats were treated with $1 \mathrm{ml} / \mathrm{kg} / \mathrm{BW}$ of $70 \%$ ethanol orally by stomach gavage, group 3: rats were treated with $1 \mathrm{ml} / \mathrm{kg} / \mathrm{BW}$ of $70 \%$ ethanol and $5 \mathrm{mg} / \mathrm{kg} /$ day of zinc sulfate orally by stomach gavage for and, group 4: rats treated with $1 \mathrm{ml} / \mathrm{kg} / \mathrm{BW}$ of $70 \%$ ethanol orally by stomach gavage and chicory within the diet for consecutive 5 days. The animals will be anesthetized and subjected to intracardiac normal saline $0.9 \% \mathrm{NaCl}$. Liver specimens were extracted for further processing. Results: vasodilatation in portal vein congestion of the hepatic sinusoids and degenerative changes of the hepatocytes. In group III, there was no inflammatory signs, but more damage was detected in hepatic parenchyma. Chicory treated samples had no signs of inflammation. hepatic parenchyma had a mild degree of degeneration. Conclusion: excessive consumption of alcohol lead to acute liver damage and both zinc and chicory had a protective role in decreasing signs of liver damage, but chicory was more protective than zinc in the preservation of liver tissue against damage.
\end{abstract}

Key Words: Ethanol, Alcohol toxicity

\section{Introduction}

Ethanol consumption in excess exert multiple adverse health effect mostly liver damage, as Ethanol is primarily eliminated by the liver ${ }^{(1)}$. Most of heavy ethanol drinking patients develop irreversible liver injury(2). Inflammatory mediators such as
TNF-alpha, Interleukin 6 and Interleukin 8 as well as oxidative stress, lipid peroxidation, and acetaldehyde toxicity play an essential role in liver injury and induction of apoptosis and liver fibrosis(3). Zinc is a potent cytoprotective agent as stabilizes and protects different molecules including proteins, DNA and microtubules against 
oxidation and degradation ${ }^{(4)} \cdot$ Chicory, a member of the Asteraceae family, is a wellknown herb possessing various biological activities. It was grown by ancient Egyptians as a medicinal plant, vegetable crop, and animal feed(5) Chicory root extract have several biological role such as antimicrobial( $^{(6)}$, antihyperglycemic ${ }^{(7)}$, immunostimulant $^{(8)}$, antitoxic ${ }^{(9)}$, anti-inflammatory $^{(10)}$, and tumor-inhibitory activities ${ }^{(11)}$.

\section{Material and Methods}

\section{Chemicals:}

Fresh chicory roots were obtained from the farm and crushed to fine pieces, then mixed with distilled water $15 \mathrm{mg} / 100 \mathrm{ml}$ for 50 minutes at $70^{\circ} \mathrm{C}$ with continuous stirring and then filtered ${ }^{(12)}$. Zinc sulfate was obtained from El- Gomhouria Company for Trading Chemicals and Medical Appliances.

\section{Experimental design:}

Forty male albino rats of local strain weighting 150-200 g. were obtained from animal house of South Valley University (Qena, Egypt). All rats were fed on balanced diet and water and allowed to be acclimatized for 10 days before the beginning of the experiment. The animals were housed in metal cages (10 in each group) and maintained under prevailing atmospheric conditions with continuous cleaning and observation. The rats were divided into four groups: Group 1: control group (normal rats without treatment). Group 2: rats treated with $1 \mathrm{ml} / \mathrm{kg} / \mathrm{bw}$ of $70 \%$ ethanol orally by stomach gavage for consecutive 5 days. Group 3: rats treated with $1 \mathrm{ml} / \mathrm{kg} / \mathrm{bw}$ of $70 \%$ ethanol and $5 \mathrm{mg} / \mathrm{kg} /$ day of zinc sulfate orally by stomach gavage for consecutive 5 days. Group 4: rats treated with $1 \mathrm{ml} / \mathrm{kg} / \mathrm{bw}$ of $70 \%$ ethanol orally by stomach gavage for consecutive 5 days and was given chicory within diet. The animals were anaesthetized by ether inhalation then subjected to an intracardiac perfusion of normal saline $0.9 \% \mathrm{Nacl}$. Liver specimens were extracted from the different groups of the control and treated animals. The specimens were put in a suitable fixative solution for further processing.

\section{Histological techniques:}

The liver specimens were be processed for each of the following methods: Semi-thin sections that will be stained with Toludine blue and examined by light microscopy as previously described ${ }^{(13)}$. Ultra-thin sections that will be stained with Uranyl acetate and Lead citrate then examined by transmission electron microscope ${ }^{(12) .}$

\section{Presentation of data:}

Data was presented in the form of light and electron photomicrographs comparing the treated specimens with the control group. The transverse diameter of each nucleus was measured in at least 5 hepatocytes in 5 slides in 5 different animals or rats. The determination of the minimal diameter" and the determination of the number of the hepatocytes within individual measurement objects are two of the many selectable built-in morphometric measurement parameters in professional image analysis programs.

\section{Statistical analysis}

Data were analyzed by SPSS software version 23. Mean, and standard deviation were used as appropriate. ANOVA (Analysis of Variance) test was used to compare the means of variables between different groups. $P$ value of $<0.05$ was considered significant, while $p<0.01$ and $p<0.001$ were considered as moderately significant, and highly significant, respectively.

\section{Results}

In group I, there was a normal architecture of the liver tissue as the hepatocytes were polygonal in shape and radiating from the central vein and cords of the hepatocytes 
were separated with blood sinusoids (Figure 1), normal appearance of hepatocyte with normal nucleus, normal rough endoplasmic reticulum and normal mitochondria (Figure 5). Vascular changes and degenerative changes occurred in liver treated with alcohol. Vascular changes in cluded vasodilatation and hyperemia of the portal vein and their branches (Figure $2 \mathrm{~A}$ ), hyperemia and congestion of the central artery branches (Figure 2B), dilatation and congestion of the hepatic sinusoids (Figure 2D, E) and dilatation of the portal vein which neutrophils circulated (Fig $2 G$ ).

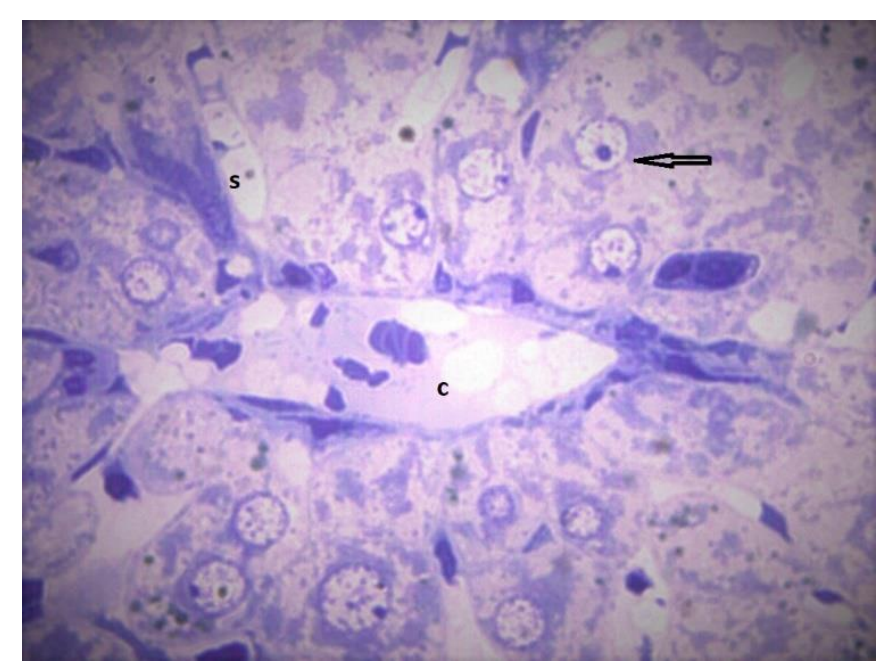

Figure 1: control group: photomicrograph of a cross section of liver of group I showing normal architecture of liver tissue as hepatocytes are polygonal (arrow) in shape radiating from central vein (c ) and cords of hepatocytes are separated with blood sinusoids(s). Toulidine blue x 1000

Hepatocytes exhibited signs of degeneration such as vacuolation of the hepatocytes (Figure 2B, D, E) and fatty degeneration (Figure 2C). Kupffer cells were enlarged and acquired highly vacuolated cytoplasm (Figure 2F). By TEM, degenerated hepatocytes had shrunken nuclei and condensed chromatin compared with the euchromatic nuclei (Figure 6A). Some hepatocytes exhibited nuclear shrinkage, pyknosis, chromatin condensation and hyalinization (Figure 6B). Degenerated hepatocytes also exhibited mitochondria hyalinization and autophagic vesicles
(Figure 6C). Neutrophils were identified in the blood sinusoids (Figure 6A) and the interstitial tissue (Figure 6D) and the portal vein branches (Figure 6F). Numerous basophiles migrated through smooth muscle fibers of the tunica media the hepatic arterial branches (Figure 6E). Liver responded to zinc administration and underwent mild improvement that had no inflammatory signs, but more damage was detected in hepatic parenchyma. Degenerative changes of moderate to severe degrees as varying the intensity of hepatocytes vacuolation (Figure 3A-D, F). 


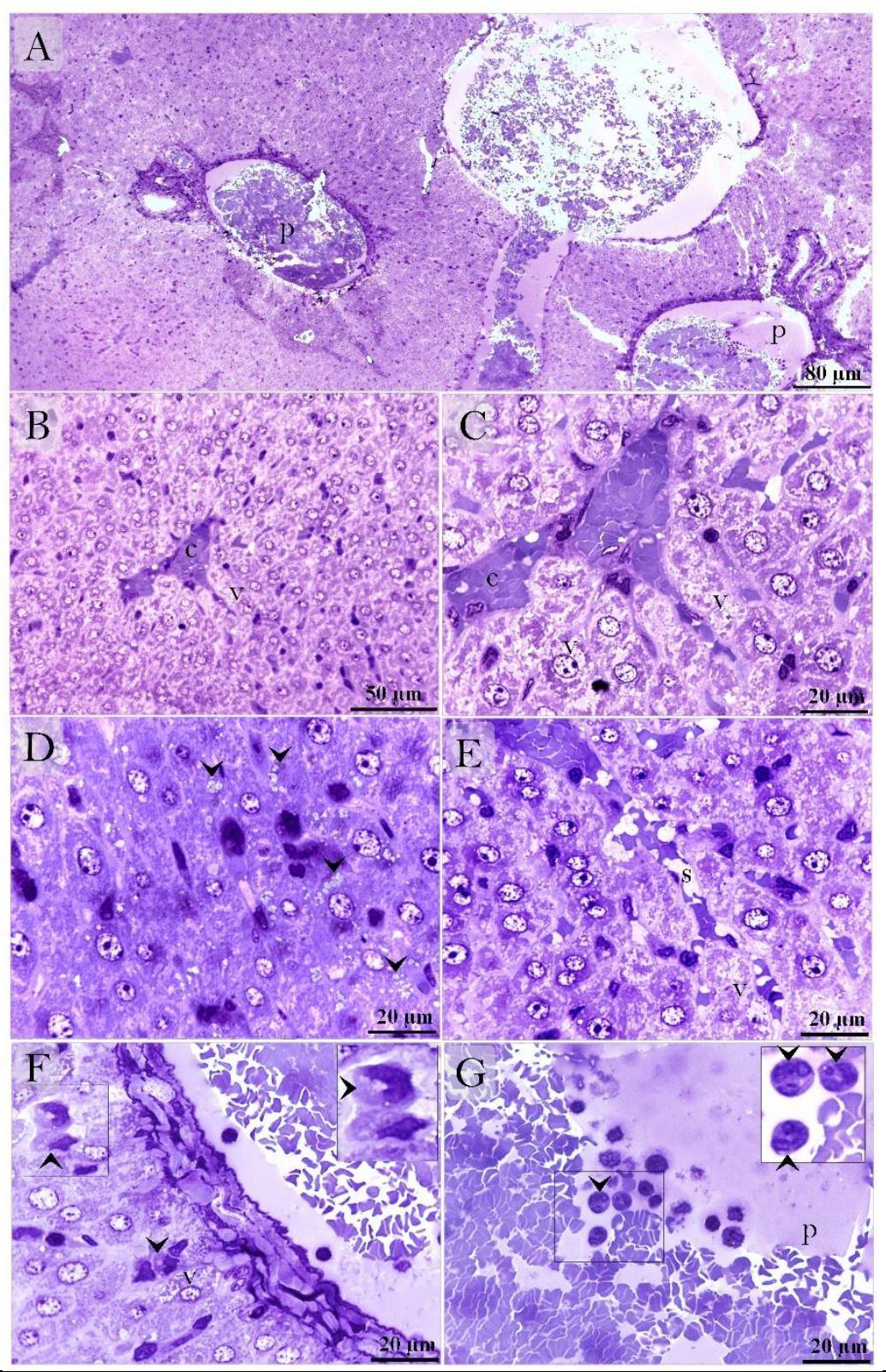

Figure 2: Vascular changes and degenerative changes indicate acute alcoholic hepatitis: A: vasodilatation and hyperemia of the portal vein and their branches (P). B: Hyperemia and congestion of the central artery branches $(C)$ and extensive vacuolation $(V)$ of the hepatocytes. $C$ : hepatocytes undergo fatty degeneration. Note lipid droplets (arrowheads). D, E: dilatation and congestion of the hepatic sinusoids. Extensive vacuolation (V) of the hepatocytes. F: activation of the Kupffer cells (arrowhead) which were enlarged and had vacuolar cytoplasm. G: Dilatation of the portal vein which contained neutrophils

Aggregation of the Perivascular Kupffer cells was observed around the central vein (Figure 3D) and hepatic sinusoids (Figure $3 F$ ). Kupffer cells were enlarged and exhibited vacuolar cytoplasm (Figure $3 \mathrm{E}$ ). Vascular changes were limited to dilatation and congestion of the hepatic sinusoids in (Figure $3 \mathrm{C}$ ). The ultrastructure features revealed hepatocytes damage extended to extensive vacuolation, chromatin disintegration, mitochondria degradation, destruction of the microvilli (Figure $7 \mathrm{~A}, \mathrm{~B}$ ). Vesicle-rich Kupffer cells was numerous between hepatocytes (Figure $7 C$ ). Chicory had a potential role to maintain hepatic parenchyma against alcohol-related injury. 
Chicory treated samples had no signs of inflammation. hepatic parenchyma mostly exhibited mild degree of degeneration that hepatocytes exhibited few vacuoles at the intermediate zone (Figure $4 \mathrm{~A}$ ), at the peripheral zone or the periportal zone (Figure 4B) and at the centro-lobular zone (Figure 4C). Chicory might retain the microstructure of hepatocytes at other areas in the peripheral zone around the portal area (Figure 4C). However, the ultrastructure picture evident that chicory-maintained hepatocytes organelles including euchromatic nucleus, rough endoplasmic reticulum, mitochondria, microvilli and secretory vesicles (Figure $8 \mathrm{~A}, \mathrm{~B}$ ). Activated Kupffer cells were also detected (Figure $8 C$ ).

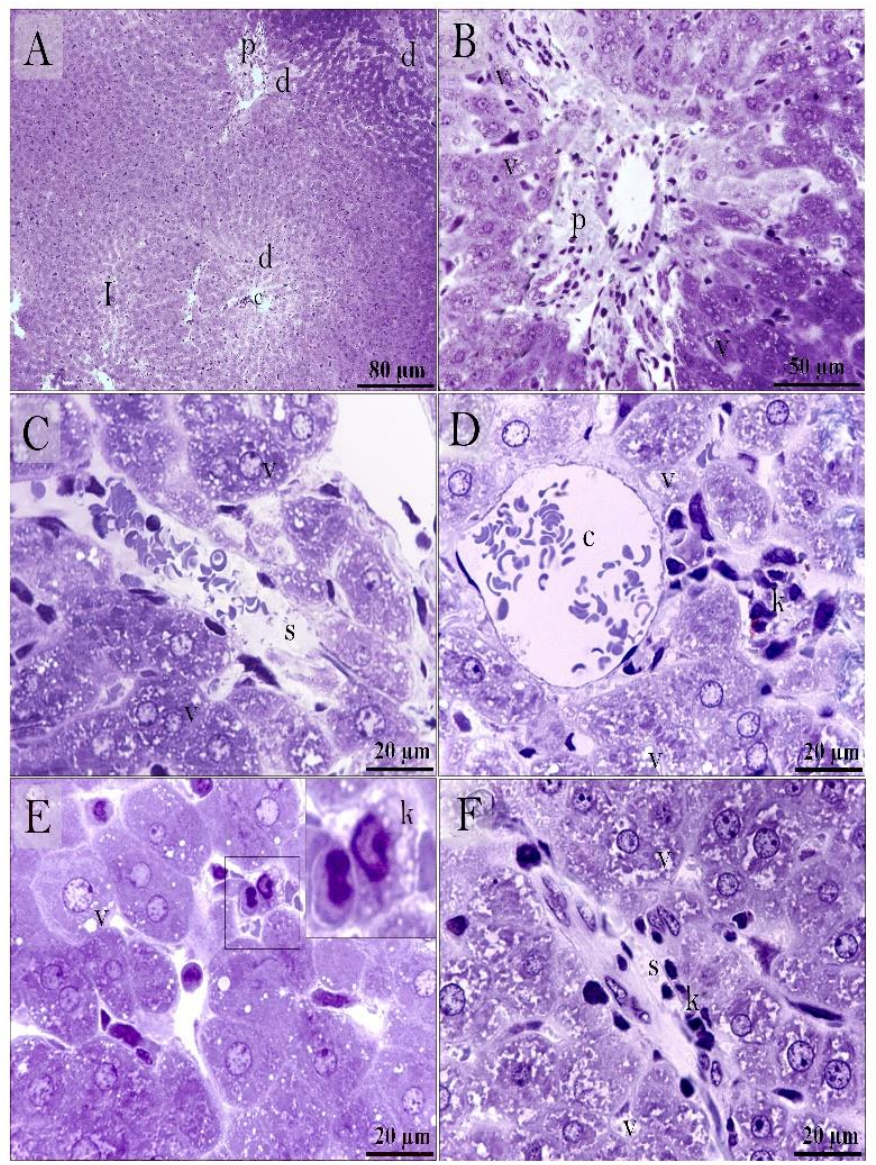

Figure 3: Effect of zinc on alcohol-related injury of the liver: A: degeneration of the hepatic parenchyma (d) was detected in the centro-lobular zone around the central vein (c), the peripheral zone around the portal area (P) and the intermediate zone (I). B-D, F: moderate to severe degree of degeneration of hepatic parenchyma as indicated by the vacuolation (v). Aggregation of the Perivascular Kupffer cells $(K)$ was observed around the central vein (C) in Figure D and portal area (p) in Figure F. Dilatation and congestion of the hepatic sinusoids in Figure C. E: degenerated hepatocytes exhibited fat droplets and cytoplasmic vacuoles (v). Note active Kupffer cell that exhibited vacuolar cytoplasm.

\section{Discussion}

Alcoholic Hepatotoxicity is a common all over the world that exceeds $83 \%$ of all cases and the almost of the severe health problems ${ }^{(14-16)}$. Ethanol administration make changes on liver tissue by generation of the reactive oxygen species as well as reduction cellular antioxidant levels, and intensification of the oxidative stress in 
different organs, essentially the liver ${ }^{(17)}$. It was noticed that kupffer cells were activated and these cells participate in production of the free radicals and cytokines, including tumor necrosis factor alpha (TNFa), which have a role in induction of the alcoholic liver disease ${ }^{(18,19)}$.

\begin{tabular}{|l|c|c|c|c|}
\hline \multicolumn{6}{|l|}{\begin{tabular}{l} 
Table 1. Comparison between mean of transverse diameter \\
of the nucleous in different groups. \\
\hline
\end{tabular}} & Number & Mean & Stand. deviation & Significance \\
\hline Group 1 & 17 & 9.0388 & 1.12293 & \\
\hline Group 2 & 17 & 5.5378 & 1.23759 & HS \\
\hline Group 3 & 17 & 6.4195 & 1.04768 & HS \\
\hline Group 4 & 17 & 9.8636 & 1.70859 & NS \\
\hline Total & 68 & 7.7149 & 2.20699 & \\
\hline
\end{tabular}

Group 1=control group, group $2=$ alcohol group, group $3=$ alcohol-zinc and group4=alcohol-chicory, HS=highly significant, NS=not significant

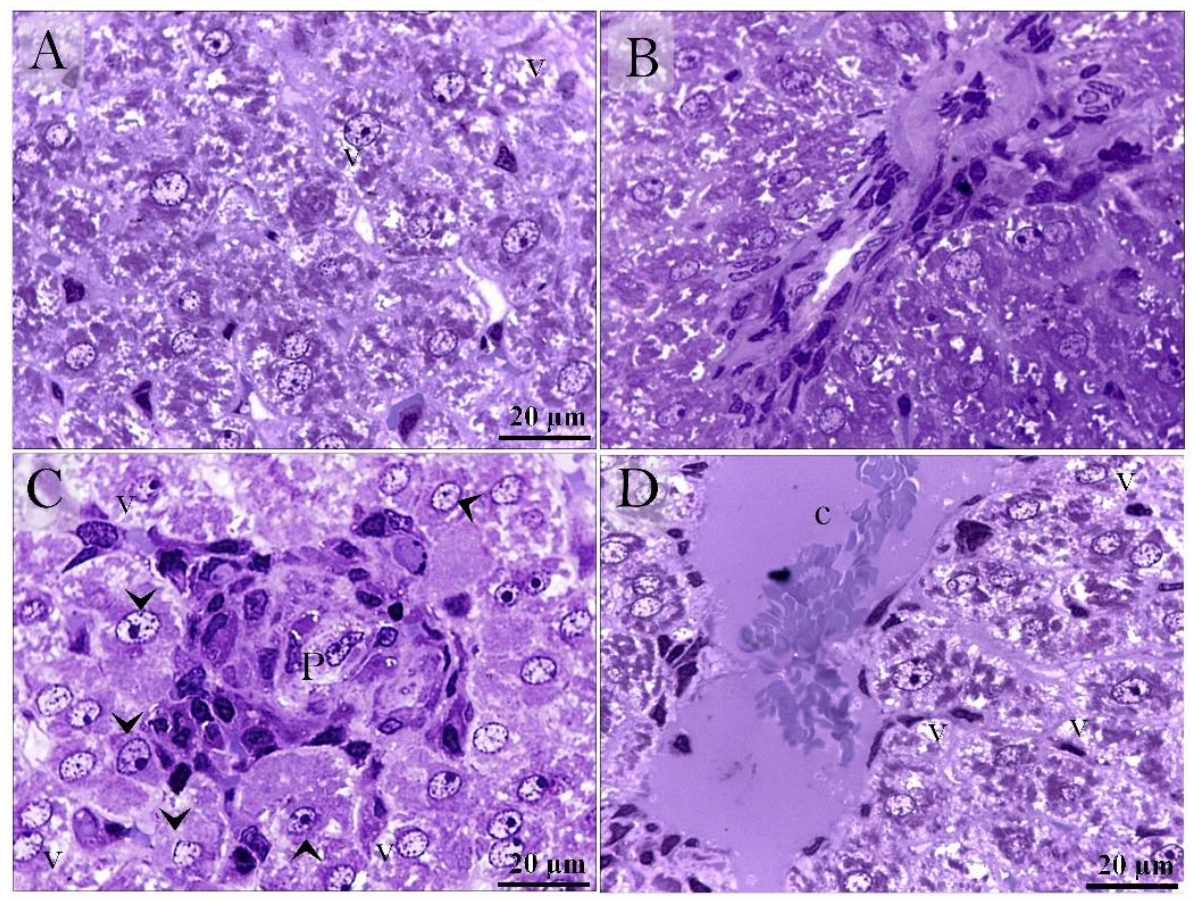

\begin{abstract}
Figure 4: Effect of chicory on alcohol-related injury of the liver: A: hepatic parenchyma mostly exhibited mild degree of degeneration that hepatocytes exhibited few vacuoles (v). B: hepatocytes exhibited few vacuoles ( $v$ ) in the peripheral zone around the portal area $(P) C$ : Normal hepatocytes (arrowheads) located in the peripheral zone around the portal area $(P)$. D: hepatocytes exhibited few vacuoles $(v)$ in the centro-lobular zone around the central vein (C).
\end{abstract}

Dietary zinc supplementation may provide protective role during alcoholic liver injury through suppression of oxidative stress and activation of antioxidant pathways ${ }^{(20)}$. Recently, herbal medicine has been used to improve liver function in cases of hepatic diseases ${ }^{(21)}$. Chicory, belongs to the
Asteraceae family. It is a popular herb serve in several biological activities. It has been used by ancient Egyptians as a vegetable crop and medicinal plant ${ }^{(5)}$. Therapeutic uses of the chicory is also commonly known for a medication of gastrointestinal and inflammatory disorders in Europe and 
Asia(22). Chicory extract have a wide range of biological effects including anti-inflammatory ${ }^{(10)}$, antitoxic $(9,23)$ Immunomodulatory $^{(24)}$, antifungals ${ }^{(6)}$. Antimicrobial ${ }^{(23,26)}$, antioxidant $^{(26,27)}$, antihyperglycemic ${ }^{(27)}$, anticarcinogenic activities ${ }^{(28)}$. In our study, we found the chicory had a protective role against the toxic effect of alcohol in liver.

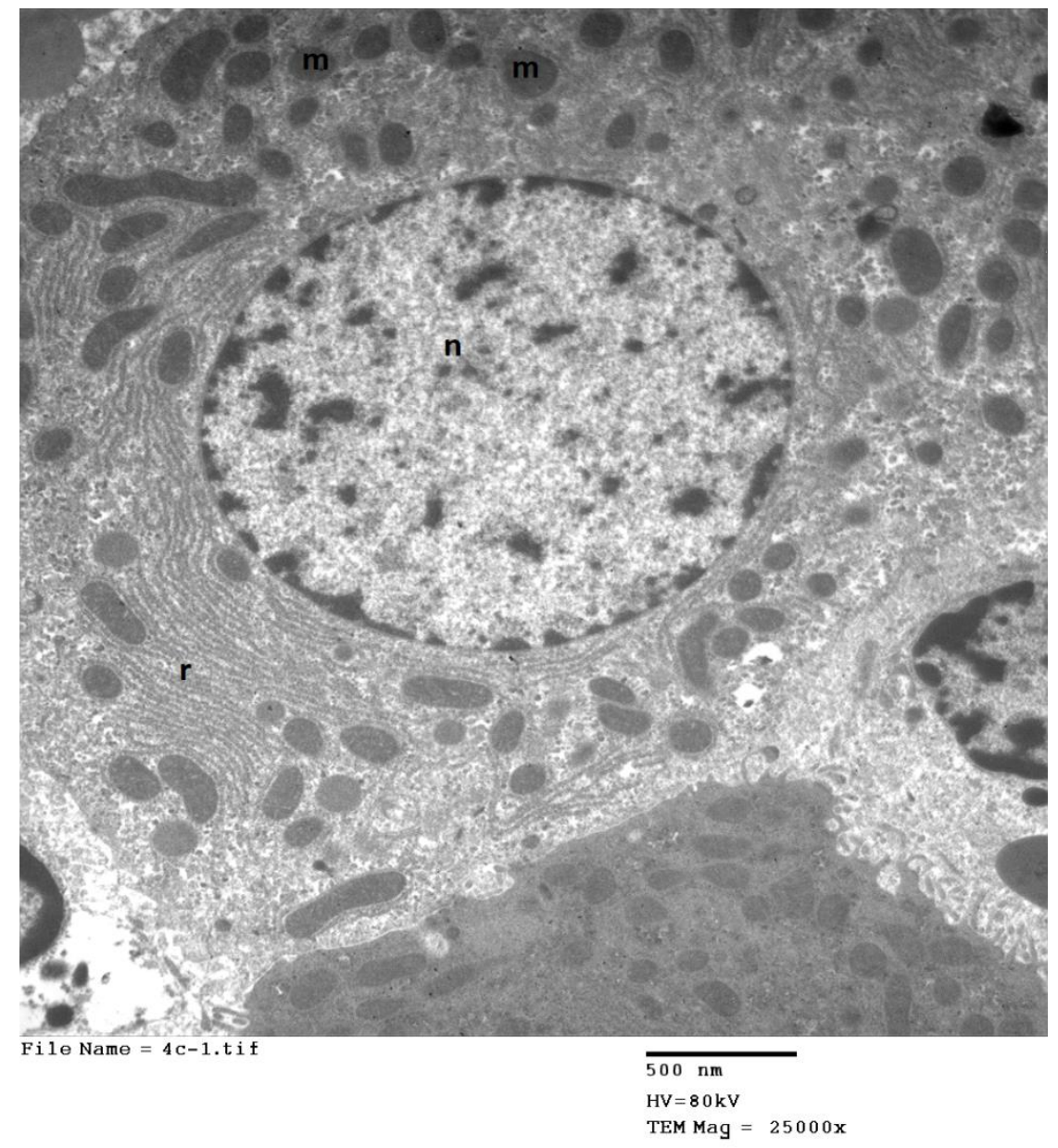

Figure 5: control group: Electromicrograph of liver tissue of group I show normal appearance of hepatocyte with normal nucleus $(n)$ normal rough endoplasmic reticulum $(r)$ and normal mitochondria $(m)$.

The protective effect included the anti-inflammatory activity, maintain normal vascular picture and the liver cells. No inflammatory response of liver was detected. No vascular changes were recognized in chicory-treated samples. While dilatation and congestion of the hepatic sinusoids occurred in zinc-treated samples. Zinc had no protective role for liver parenchyma in acute liver injury degeneration. Hepatocytes vacuolation was identified according to location of hepatocytes in different metabolic zones. TEM examination showed hepatocytes damage extended to extensive vacuolation, chromatin disintegration, mitochondria degradation, destruction of the microvilli. Unlike Zhou, Wang et al.(20) zinc supplementation prevented ethanolinduced chronic liver alcoholic injury via inhibition of oxidative stress. Microstructure of certain periportal areas appeared normal but the ultrastructure picture evident that chicory maintained the organelles of the periportal hepatocytes including nucleus, rough endoplasmic reticulum, mitochondria, microvilli as well as the secretory 
activity of hepatocytes. However, mitochondrial damage was noticeable. Pattern of zonal pathology could be attributed to variations of the oxygen gradient and zonation of metabolism as described by $\left(\right.$ Kietzmann 2017) ${ }^{(29)}$.

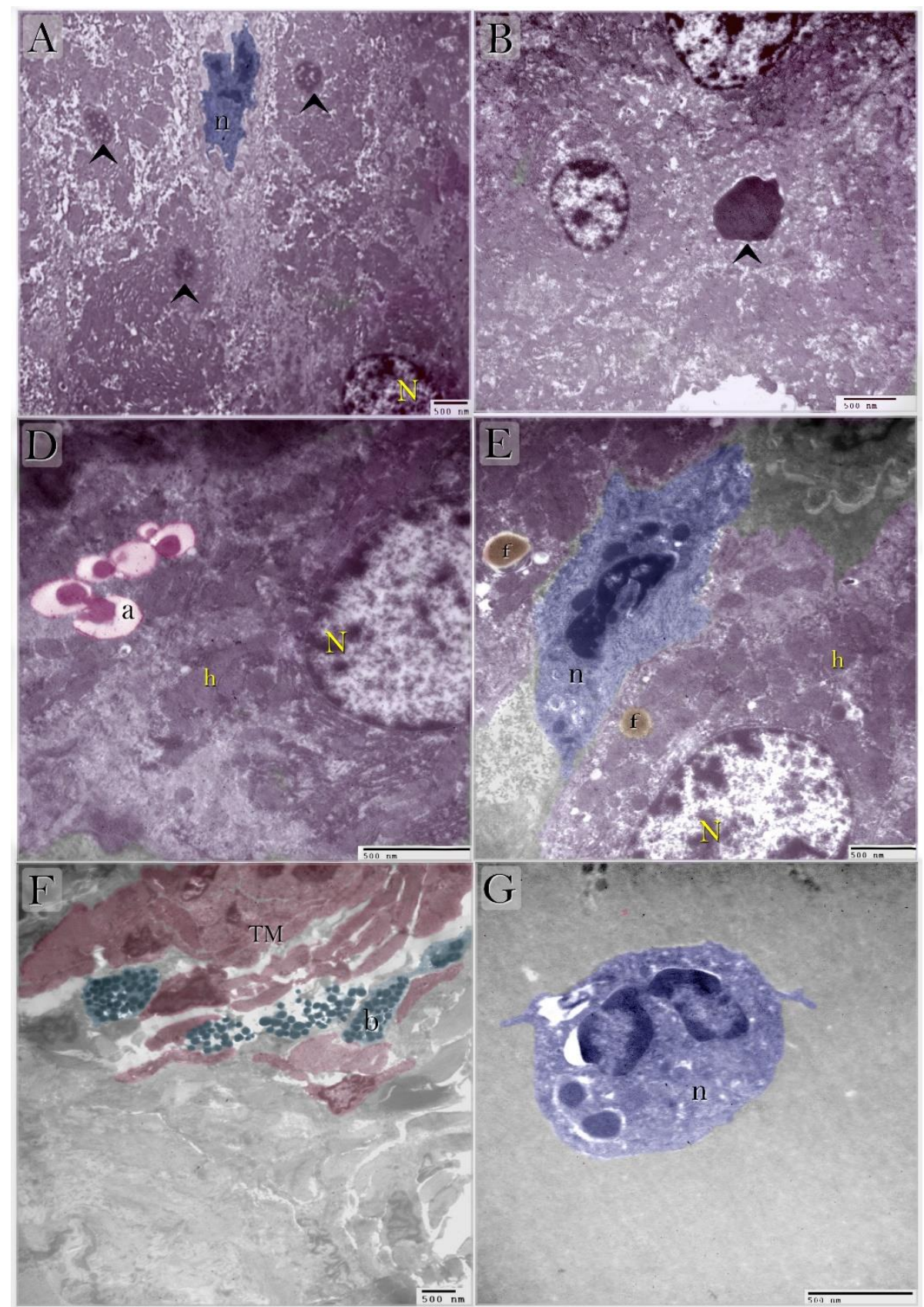

Figure 6: Degenerative changes of hepatocytes during acute alcoholic hepatitis A: degenerated hepatocytes had shrunken nuclei and condensed chromatin (arrowheads). note euchromatic nucleus $(N)$. neutrophil in blood sinusoids $(n)$. B: some hepatocytes exhibited nuclear shrinkage, pyknosis, chromatin condensation and hyalinization. C: degenerated hepatocytes exhibited mitochondria hyalinization ( $h$ ), autophagic vesciles (a). note euchromatic nucleus (N). D: degenerated hepatocytes exhibited mitochondria hyalinization (h) and fat droplets ( $f$ ). note interstitial neutrophil (n). E: numerous basophiles (b) penetrated the tunica media (TM) of one of the hepatic arterial branches. note smooth muscles (red colored) of the tunica media. F: neutrophil (n) circulating in the portal vein. 

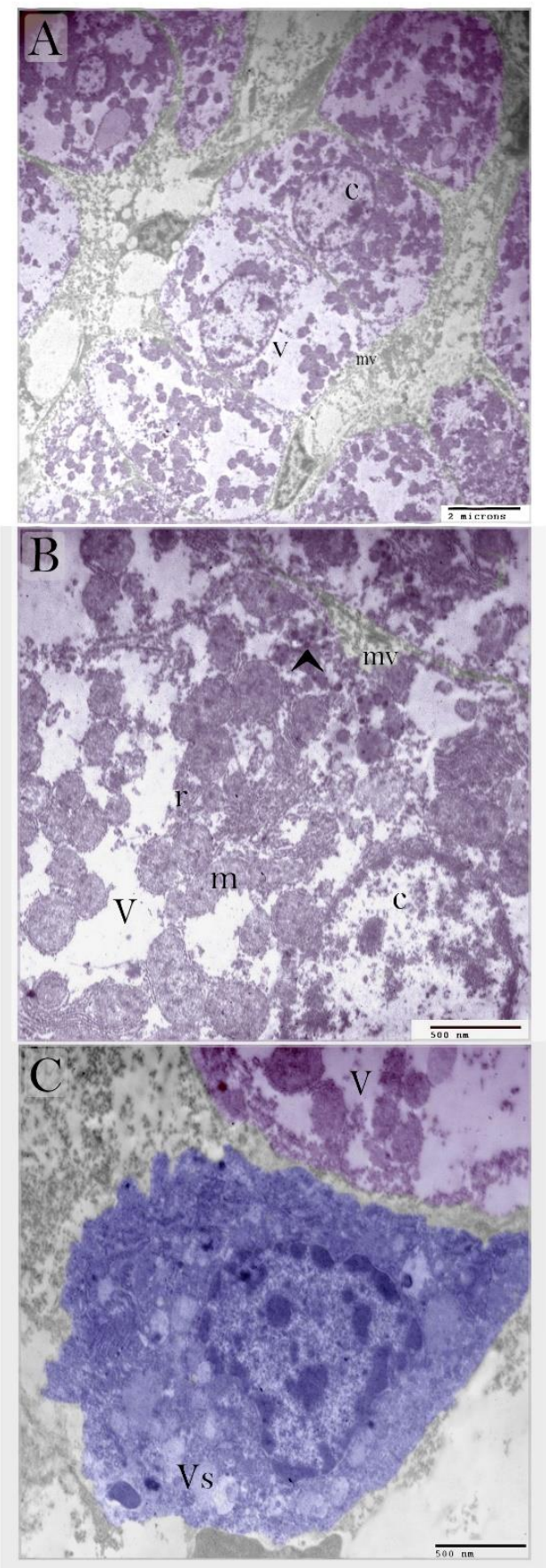

Figure 7: Effect of zinc on alcohol-related injury of the hepatocytes: A, B: degenerated hepatocytes exhibited extensive vacuolation ( $v$ ), disintegrated chromatin (c), degraded mitochondria that had few cristae and dense bodies (arrowhead), destructed microvilli (mv). Few rough endoplasmic reticulum ( $r$ ). C: Activated Kupffer cells (blue colored cell) rich in vesicles (vs). degenerated hepatocyte exhibited extensive vacuolation (v).

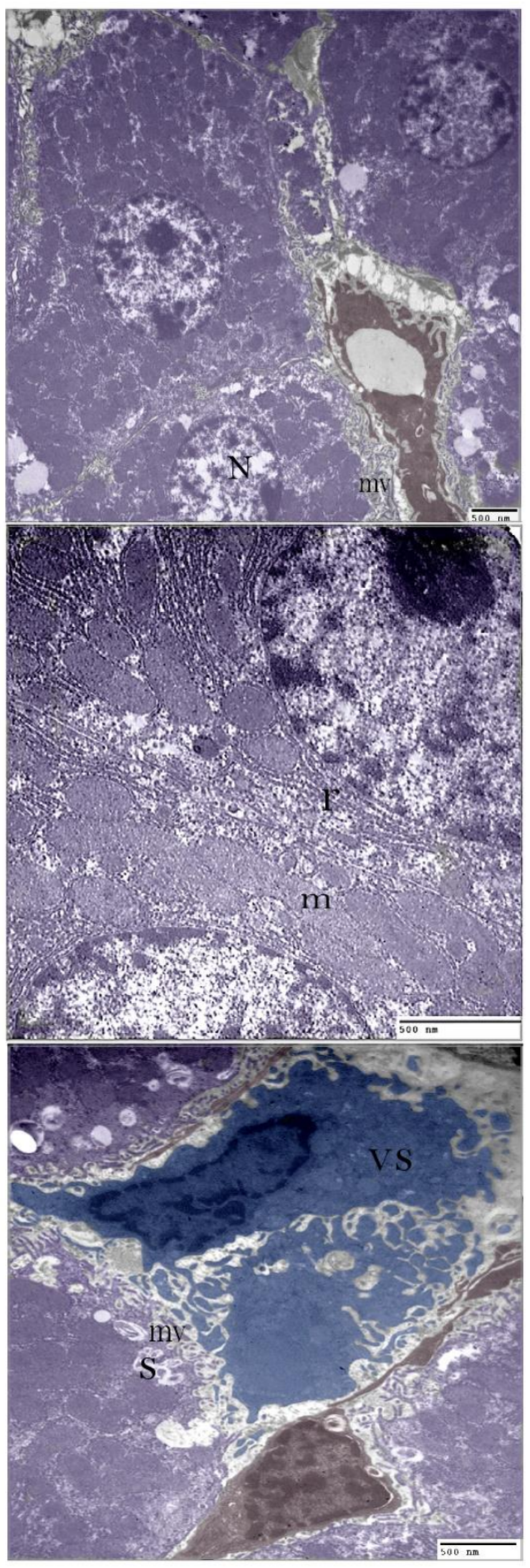

Figure 8: Effect of chicory on alcohol-related injury of the hepatocytes: A, B: Hepatocytes had euchromatic nucleus with distinct nucleuses $(\mathrm{N})$, rough endoplasmic reticulum $(r)$, mitochondria $(m)$, and distinct microvilli $(\mathrm{mv})$. C: Activated Kupffer cells (blue colored cell) rich in vesicles (vs). Hepatocytes had distinct microvilli (mv), secretory vesicles (s).
In alcohol toxicity, Kupffer cells were enlarged and acquired highly vacuolated cytoplasm. These results indicates that activation of endosomal-lysosomal system 
play an essential role modulating and inhibition of the inflammatory response(30).

\section{Conclusion}

Zinc has a protective role, as an anti-inflammatory, however, it failed to improve the degenerative effect of alcohol toxicity. Chicory prevents inflammatory response and partially preserves liver parenchyma during alcohol toxicity. Thus, chicory provides more protective effect against the alcohol toxicity rather than zinc.

\section{References}

1. Berg JM, Tymoczko JL, Stryer L. Ethanol Alters Energy Metabolism in the Liver. Biochemistry. New York: W H Freeman; 2002. $5^{\text {th }}$ edition. Sec.30.5.

2. Ismail M, and Riely C. Alcoholic Fatty Liver. emedicine from WebMD. 2006. October 31.

3. Longstreth, George, F., Zieve and David (eds). Alcoholic Liver Disease. . MedLinePlus: Trusted Health Information for You. Bethesda, MD: US National Library of Medicine \& National Institutes of Health.2009. Retrieved 27 January 2010.

4. Perry DK, Smyth MJ, Stennicke HR, et al. Zinc is a potent inhibitor of the apoptotic protease, caspase-3. A novel target for zinc in the inhibition of apoptosis. J Biol Chem.1997. 272 (30): 18530-18533.

5. Alloush GA, Belesky DP, and Clapham WM. Forage chicory: a plant resource for nutrient-rich sites. J Agron Crop Sci.2003. 189: 96-104.

6. Mares D, Romagnoli C, Tosi B, Andreotti E, Chillemi G, and Poli F. Chicory extracts from Cichorium intybus L. as potential antifungals. Mycopathologia.2005. 160 (1): 85-91.

7. Azay-Milhau J, Ferrare K, Leroy J, et al. Antihyperglycemic effect of a natural chicoric acid extract of chicory (Cichorium intybus L.): a comparative in vitro study with the effects of caffeic and ferulic acids. J Ethnopharmacol. 2013. 150 (2): 755-760.

8. Kim JH, Mun YJ, Woo WH, Jeon KS, An $\mathrm{NH}$, and Park JS. Effects of the ethanol extract of Cichorium intybus on the immunotoxicity by ethanol in mice. Int Immunopharmacol. 2002. 2 (6): 733744 .

9. Hassan HA. and Yousef MI. Ameliorating effect of chicory (Cichorium intybus L.)-supplemented diet against nitrosamine precursors-induced liver injury and oxidative stress in male rats. Food Chem Toxicol.2010. 48 (8-9): 2163-2169.

10. Cavin C, Delannoy M, Malnoe A. Inhibition of the expression and activity of cyclooxygenase-2 by chicory extract. Biochem Biophys Res Commun. 2005. 327 (3): 742-749.

11. Lee KT, Kim JI, Park HJ, Yoo KO, Han $\mathrm{YN}$, and Miyamoto K. Differentiationinducing effect of magnolialide, a 1 beta-hydroxyeudesmanolide isolated from Cichorium intybus, on human leukemia cells. Biol Pharm Bull. 2002. 23 (8): 1005-1007.

12. Soliman SA. and Abd-Elhafeez HH. Mesenchymal Cells in Cartilage Growth and Regeneration "An Immunohistochemical and Electron Microscopic Study". J Cytol Histol. 2016. 7: 437.

13. Soliman S. and Emeish W. Morphological Alternations of Intraepithelial and Stromal Telocytes in Response to Salinity Challenges. bioRxiv.2017.

14. Al-Harbi NO, Imam F, Nadeem A, AlHarbi MM, Iqbal $M$. and Ahmad SF. Carbon tetrachloride-induced hepatotoxicity in rat is reversed by treatment with riboflavin. Int Immunopharmacol.2014. 21 (2): 383-388.

15. Cemek M, Aymelek F, Buyukokuroglu ME, Karaca T, Buyukben A, and Yilmaz F. Protective potential of Royal Jelly against carbon tetrachloride inducedtoxicity and changes in the serum sialic acid levels. Food Chem Toxicol. 2010.48 (10): 2827-2832.

16. Siegel R, Ma J, Zou Z, Jemal A. Cancer statistics, 2014. CA Cancer J Clin.2014. 
64 (1): 9-29.

17. Dey A. and Cederbaum Al. Alcohol and oxidative liver injury. Hepatology. 2006. 43(2 Suppl 1): S63-74.

18. Adachi Y, Bradford BU, Gao W, Bojes $\mathrm{HK}$, and Thurman RG. Inactivation of Kupffer cells prevents early alcoholinduced liver injury. Hepatology.1994. 20(2): 453-460.

19. limuro Y, Gallucci RM, Luster MI, Kono $\mathrm{H}$, and Thurman RG. Antibodies to tumor necrosis factor alfa attenuate hepatic necrosis and inflammation caused by chronic exposure to ethanol in the rat. Hepatology.1997. 26 (6): 1530-1537.

20. Zhou Z, Wang L, Song Z, Saari JT, McClain CJ. and Kang YJ. Zinc supplementation prevents alcoholic liver injury in mice through attenuation of oxidative stress. Am J Pathol.2005. 166 (6): 1681-1690.

21. Ashry KM, El-Sayed YS, Khamiss RM. and El-Ashmawy IM. Oxidative stress and immunotoxic effects of lead and their amelioration with myrrh (Commiphora molmol) emulsion. Food Chem Toxicol.2010. 48 (1): 236-241.

22. Street RA, Sidana J. and Prinsloo G. Cichorium intybus: Traditional Uses, Phytochemistry, Pharmacology, and Toxicology. Evid Based Complement Alternat Med. 2013: 579319.

23. Kim TW. and Yang KS. Antioxidative effects of cichorium intybus root extract on LDL (low density lipoprotein) oxidation. Arch Pharm Res.2001. 24(5): 431-436.

24. Amirghofran Z, Azadbakht M. and Karimi MH. Evaluation of the immunomodulatory effects of five herbal plants. J Ethnopharmacol.2000. 72 (1-2): 167-172.

25. Petrovic J, Stanojkovic A, Comic L. and Curcic S. Antibacterial activity of Cichorium intybus. Fitoterapia.2004. 75 (7-8): 737-739.

26. Liu H, Wang Q, Liu Y, Chen G, and Cui J. Antimicrobial and antioxidant activities of Cichorium intybus root extract using orthogonal matrix design. J Food Sci.2013. 78 (2): M258-263.

27. El-Sayed YS, Lebda MA, Hassinin M, and Neoman SA. Chicory (Cichorium intybus L.) root extract regulates the oxidative status and antioxidant gene transcripts in $\mathrm{CCl}_{4}$-induced hepatotoxicity. PLoS One.2015. 10 (3): e0121549.

28. Hazra B, Sarkar R, Bhattacharyya S, and Roy P. Tumour inhibitory activity of chicory root extract against Ehrlich ascites carcinoma in mice. Fitoterapia.2002. 73 (7-8): 730-733.

29. Kietzmann T. Metabolic zonation of the liver: The oxygen gradient revisited. Redox biology. 2017. 11: 622630.

30. Cubero F, and Nieto N. Kupffer cells and alcoholic liver disease. Rev Esp Enferm Dig 2006 Jun; 98(6):460-72.

31. Ge W, Li D, Gao Y, and Cao X. The Roles of Lysosomes in Inflammation and Autoimmune Diseases. Int Rev Immunol.2015. 34 (5): 415-431. 